\title{
First records of Isohypsibius pushkini Tumanov, 2003 (Tardigrada, Eutardigrada, Hypsibiidae) from Poland
}

\author{
ŁUKASZ KACZMAREK ${ }^{1}$, BARTŁOMIEJ GOŁDYN², MICHAŁ CZYŻ ${ }^{3}$ \\ and LUKASZ MICHALCZYK ${ }^{4}$ \\ ${ }^{1}$ Department of Animal Taxonomy and Ecology, Adam Mickiewicz University, Umultowska 89, \\ 61-614 Poznań, Poland; e-mail: kaczmar@amu.edu.pl \\ ${ }^{2}$ Department of General Zoology, Adam Mickiewicz University, Umultowska 89, 61-614 Poznań, \\ Poland; e-mail: glodny@amu.edu.pl \\ ${ }^{3}$ Senckenberg Museum für Naturkunde Görlitz, PF 300 154, D-02806 Görlitz, Germany; \\ e-mail: czyzu@amu.edu.pl \\ ${ }^{4}$ Centre for Ecology, Evolution and Conservation, School of Biological Sciences, \\ University of East Anglia, Norwich NR4 7TJ, United Kingdom; e-mail: LM@tardigrada.net \\ Corresponding author: Łukasz Kaczmarek, kaczmar@amu.edu.pl
}

(Received on 28 May 2010; Accepted on 29 September 2010)

\begin{abstract}
First records of Isohypsibius pushkini from small ponds in western Poland are described. So far, these are the only records of this species apart from its type locality in Russia. We present some remarks on the ecology of the species, as well. Moreover, we present the first ever microphotographs of I. pushkini.
\end{abstract}

Keywords: Isohypsibius pushkini, Tardigrada, Hypsibiidae, Poland, first record

\section{INTRODUCTION}

Up to now, 98 tardigrade species have been reported from Poland (KACZMAREK 2008), including 19 of the genus Isohypsibius. In this paper, a new species to the fauna of Poland, Isohypsibius pushkini Tumanov, 2003, is reported from small ponds in western Poland. Some remarks on the ecology of the species are also described. This species was described several years ago from a small ditch in the Otdelnyi Park in Pushkin City (St. Petersburg Province, Russia). So far, this is the only record of this species apart from its type locality.

\section{MATERIAL AND METHODS}

The tardigrades were found in zooplankton samples collected on the occasion of a study on the life history of the fairy shrimp Eubranchipus grubii (Crustacea: 

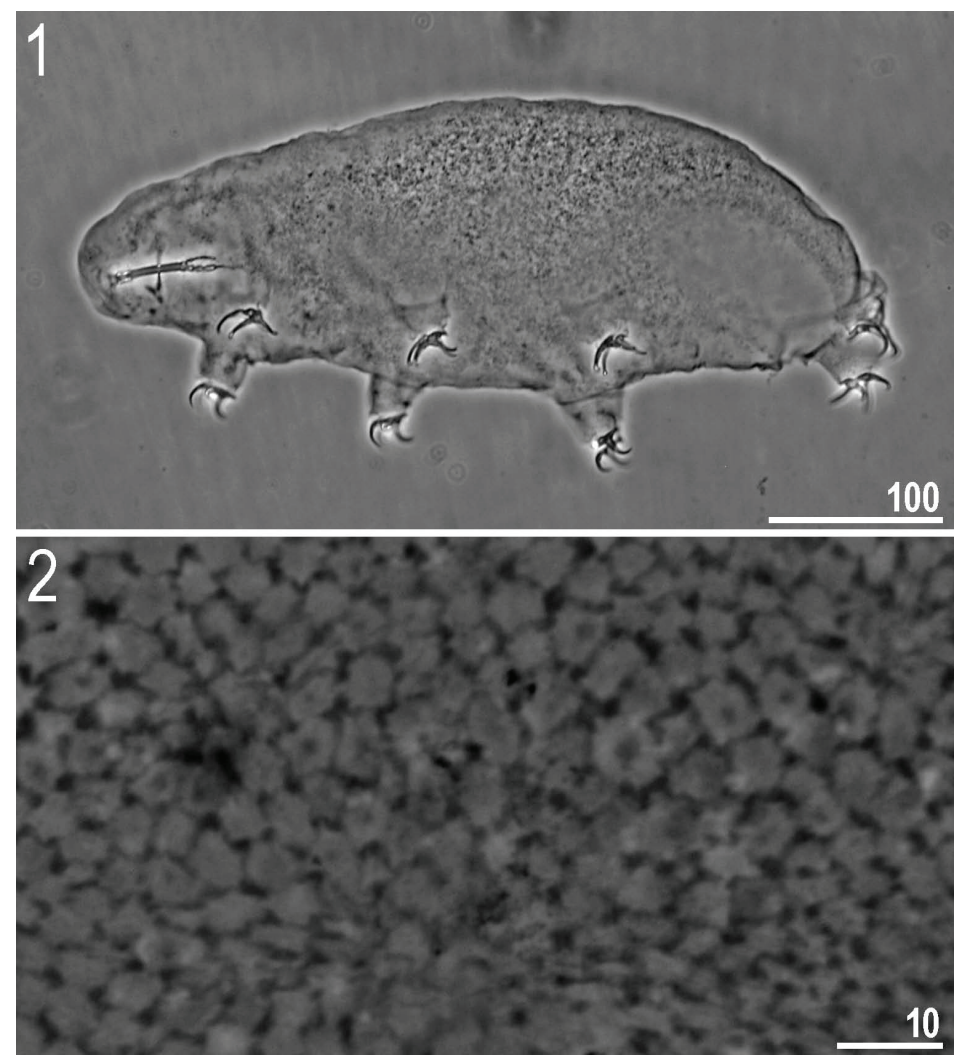

Figs. 1-2. Isohypsibius pushkini: (1) habit (ventro-lateral view); (2) dorsal cuticle ornamentation. Scale bars in $\mu \mathrm{m}$

Anostraca) (B. GoŁDYn, unpubl. data). The samples were collected each week, starting from February 2009 to June 2010, from 9 temporary ponds situated in the agricultural landscape of the Kaźmierz commune (Greater Poland Province, West Poland). The plankton was collected with a net (mesh size $45 \mu \mathrm{m}$ ). Physicochemical properties of water (temperature, $\mathrm{pH}$, dissolved oxygen content, and conductivity) were measured using the Hatch portable meter HQ30d. The samples were examined under a stereomicroscope, directly after transporting them to the laboratory. Tardigrades were found in samples from ponds Brzeźno-West (BRW, coordinates: $52^{\circ} 29^{\prime} 25^{\prime \prime} \mathrm{N}$; 16 $\left.6^{\circ} 36^{\prime} 04^{\prime \prime} \mathrm{E}\right)$ and Topole-Góra (TPG, coordinates: $52^{\circ} 29^{\prime} 02^{\prime \prime} \mathrm{N}$; 16 $\left.37^{\circ} 05^{\prime \prime} \mathrm{E}\right)$. All specimens were next mounted in Hoyer's medium, examined and photographed with an Olympus BX41 phase contrast microscope. I. pushkini specimens were identified using the original description by Tumanov (2003). The slides are stored at the Natural History Collections, Adam Mickiewicz University, Poznań, Poland. 


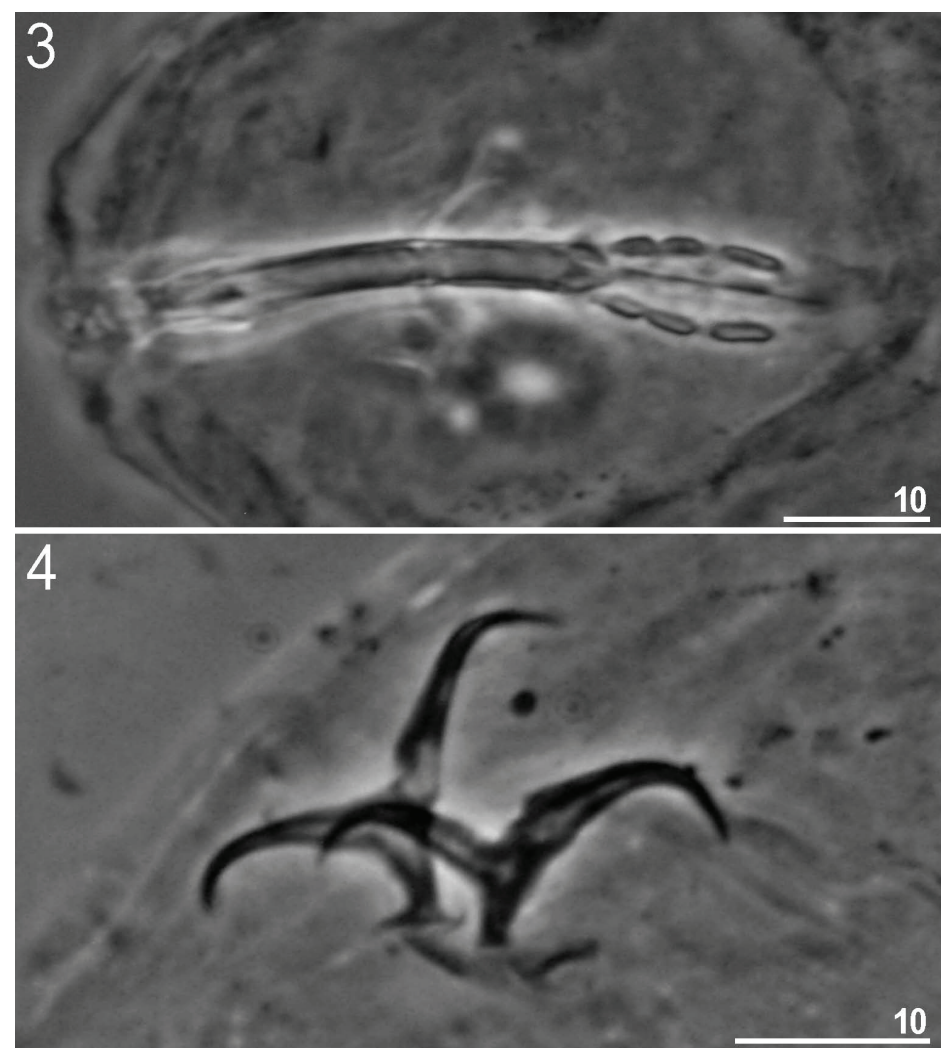

Figs. 3-4. Isohypsibius pushkini: (3) buccal apparatus (ventro-lateral view); (4) claws III. Scale bars in $\mu \mathrm{m}$

\section{RESULTS}

\section{Taxonomic account}

Phylum: Tardigrada (Spallanzani, 1777)

Class: Eutardigrada (Richters, 1926)

Order: Parachela Schuster et al., 1980

Family: Hypsibiidae Pilato, 1969

Subfamily: Hypsibiinae Pilato, 1969

Genus: Isohypsibius Thulin, 1928

Isohypsibius pushkini Tumanov, 2003

(Figs. 1-4)

Material examined: 27 specimens from 2 ponds ( 8 from BRW and 19 from TPG). 
Short diagnosis: Adult specimens $360.0-463.5 \mu \mathrm{m}$ long. Body white or transparent, often with visible green algae in the intestine (Fig. 1). Eyes present in most specimens. Dorsal cuticle covered by small granules connected by thin striae, forming a reticular design (Fig. 2). Bucco-pharyngeal apparatus of Isohypsibius type (Fig. 3). Oral cavity armature very simple, composed of one band of small teeth situated on the dorsal and ventral side in the posterior part of the oral cavity (in larger specimens, a band of minute teeth in the anterior part is also present). Pharynx oval, with 3 macroplacoids (length configuration 2-1-3). Microplacoid and septulum absent. Claws of Isohypsibius type (Fig. 4). Primary branches of claws I-III without accessory points, but claws IV with well-developed accessory points. Lunules present on all claws except internal I-III. Cuticular bars present near the base of internal claws I-III. Eggs smooth, laid in exuvia.

Differential diagnosis: With regard to the dorsal cuticle design, I. pushkini is most similar to I. tuberculatus Pilato \& Catanzaro, 1989, but differs from it by a larger body size, the absence of a constriction in macroplacoid III, and the presence of cuticular bars near claws I-III.

Distribution: Palaearctic: Europe: Poland (Greater Poland Province) and Russia (St. Petersburg Province).

\section{Ecological remarks}

I. pushkini is likely to be an obligatory freshwater species, as it was found only in small ponds and a wet ditch. During the present study, living adult specimens and exuvia with eggs were observed in 2 of the 9 ponds sampled. Both ponds are relatively small (surface area: TPG $600 \mathrm{~m}^{2}$; BRW $1170 \mathrm{~m}^{2}$ ) and shallow (maximum depth: TPG $80 \mathrm{~cm}$; BRW $130 \mathrm{~cm}$ ). Only arable fields are present in the catchments of the ponds, and various cereals are cultivated there. TPG is surrounded by 18 poplars (Populus sp.), while there are no trees near BRW.

The water level is very unstable in both ponds, TPG being one of the most ephemeral pools sampled (drying each year for at least 6 months, totally devoid of water in 2006-2008), while BRW is more stable, completely drying out for only a month per year on average (e.g. in 2008 it did not dry out at all). The edges of the ponds are covered by amphibiotic vegetation (TPG: Agrostis stolonifera; BRW: Sparganium erectum and Carex acutiformis), while the central part is dominated by filamentous algae in TPG and by Ceratophyllum demersum in BRW. In both ponds, I. pushkini was found for the first time on 10 March 2010 (13 months after the samplings started and 20 days after the ponds were refilled due to snowmelt). At that time the ponds were covered with a thin $(c a .1 \mathrm{~cm})$ layer of ice, and water temperature was about $3^{\circ} \mathrm{C}$. The species was recorded also during 4 successive samplings (the last record on 7 April 2010).

The maximum water temperature recorded during the 5 positive samplings was $11.2^{\circ} \mathrm{C}$ in $\mathrm{TPG}$ and $8^{\circ} \mathrm{C}$ in BRW. Water $\mathrm{pH}$ was between 5.52 and 7.66 in $\mathrm{BRW}$ and between 6.43 and 7.61 in TPG; dissolved oxygen: $9.42-12.03 \mathrm{mgO}_{2} \cdot \mathrm{dm}^{-3}$ in BRW and 9.65-14.96 $\mathrm{mgO}_{2} \cdot \mathrm{dm}^{-3}$ in TPG; water conductivity: $57-104 \mu \mathrm{S} \cdot \mathrm{cm}^{-1}$ in BRW and 
$137-245 \mu \mathrm{S} \cdot \mathrm{cm}^{-1}$ in TPG. Oxygen content was higher at the time when I. pushkini was found in plankton than in the period when the species was not recorded (one-way ANOVA: $F=4.285, P=0.044$ ).

Living individuals of I. pushkini were observed in the samples mainly crawling on small pieces of decaying plants floating in water, and therefore were probably accidental elements of the zooplankton samples. I. pushkini seems to be a benthic or periphytic herbivorous species, for green algae were observed in the intestine of some individuals. It is possible that I. pushkini is an early spring species, since it was found only one month after the snow had melted, when the water temperature was the lowest and oxygen concentrations were higher than average. Moreover, shortly after the melting, the species was less exposed to competition and predation, as then only small amounts of other active benthic invertebrates were found there.

Acknowledgements: The research was supported by the Polish Ministry of Science and Higher Education (grant no. N N304 340033 ).

\section{REFERENCES}

KaczmareK Ł. 2008. Niesporczaki (Tardigrada) [Water bears (Tardigrada)]. In: Fauna Polski - charakterystyka i wykaz gatunków [The fauna of Poland - characteristics and list of species] (Bogdanowicz W., Chudzicka E., Pilipuk I., Skibińska E., Eds), 3: 543-548, Muzeum i Instytut Zoologii PAN, Warszawa.

Tumanov D. V. 2003. Four new Isohypsibius species from Russian fresh waters (Tardigrada, Hypsibiidae). Bull. Inst. Roy. Sci. Natur. Belg. Biol. 73: 183-189. 